\title{
O SISTEMA EDUCACIONAL E SEUS IMPASSES FRENTE A COORDENAÇÃO PEDAGÓGICA
}

\section{ARTIGO ORIGINAL}

SANTOS, Natalina Moraes ${ }^{1}$

OLIVEIRA, Edilson Brito de ${ }^{2}$

SANTOS, Natalina Moraes. OLIVEIRA, Edilson Brito de. 0 sistema educacional e seus impasses frente a coordenação pedagógica. Revista Científica Multidisciplinar Núcleo do Conhecimento. Ano 04, Ed. 08, Vol. 03, pp. 18-26. Agosto de 2019. ISSN: 2448-0959

\section{RESUMO}

O questionamento apresentado neste trabalho teve origem durante os estudos do curso em "Formação pela Escola" oferecida pelo FNDE (Fundo Nacional de Desenvolvimento da Educação) via Secretaria Municipal de Educação "Competências Básicas", encontrou motivação para a sua elaboração a partir das reflexões mediante o aprendizado das Políticas Públicas na área da educação executada pelo Governo Federal, o financiamento dessas politicas e o papel do FNDE no apoio a efetivação da mesma. Compreendendo que toda classe educacional culminam de um mesmo

\footnotetext{
${ }^{1}$ Mestrado em Organização e gestão de centros educativos- Universidade Iberoamericana, Pós-graduação em Gestão escolar e Coordenação Pedagógica- W-pós. Pós-graduação em Geografia e meio ambiente. Graduação em Pedagogia- ULBRA. 2 Graduado em Pedagogia pela Unesulbahia Faculdades Integradas do extremo Sul da Bahia e Graduado em Ciências Sociais pela Universidade Estadual de Santa Cruz - UESC, Pós graduado em Políticas Públicas pela Faculdade Nossa Senhora de Lourdes - FNSL, Pós graduado em Gestão Escolar pela Universidade Castelo Branco, Mestre em Ciência da Educação pela Lusófona e Graduando em BI Humanidades com Acesso ao Curso de Direito pela Universidade Federal do Sul da Bahia - UFSB.
} 
objetivo, que é uma educação pública de qualidade a todos, resolve-se então destacar um dos impasses enfrentado pela coordenação pedagógica que, em uma visão pessoal, atrapalha a realização de tal objetivo dentro das instituições educacional quando não tratada com significância, uma vez que, este profissional precisa de autonomia, pois as atuais Politicas Públicas Educacionais e alguns princípios administrativos gerenciais acabam comprometendo ao que tange no processo de gestão do trabalho da coordenação dentro das instituições escolares, principalmente nos aspectos que exprime relação ao controle das ações docentes e ao alcance do resultado de um Ensino de Qualidade.

Palavras-Chave: FNDE, coordenador pedagógico, autonomia.

\section{INTRODUÇÃO}

A educação é estimada como um bem em si, pelas oportunidades que oferece de enriquecimento intelectual, cultural, social e profissional. Porém, a despeito de toda a sua estima, não se tornou prioridade das políticas governamentais e principalmente municipais. Com o objetivo de atingir uma educação de qualidade o MEC (Ministério da Educação) se vinculou a alguns órgãos, entre eles destacamos o Fundo Nacional de Desenvolvimento da Educação (FNDE), que de acordo com Moreira e Rizzoti (2009, p. 40), "Compete ao FNDE à função redistributiva da contribuição social do salário-educação". Do montante, $10 \%$ são aplicados em programas, projetos e ações voltados para universalização da educação básica [...].". É perceptível a importância que esse órgão tem na promoção de uma educação de qualidade, igualitária e autônoma.

Como parte do sistema de ensino, cada escola tem a responsabilidade de propiciar o acesso á educação, empenhada em garantir o sucesso escolar dos alunos. Para isso, Moreira e Rizzoti (2009, p.15), dizem ainda que "[...] para cumprir esta finalidade, a escola organiza sua gestão com base em um conjunto de normas e procedimentos provenientes do sistema de administração pública da educação ao qual está vinculada". Neste trabalho conclusivo gostaria de identificar um problema educacional dentro da comunidade a qual estou inserida apresentando uma análise crítica. 
A escola em sentido genérico e em todos os seus níveis, compartilha muitas das características das organizações sociais em sua intenção de alcançar objetivos com a maior eficácia e o menor custo institucional. O conhecimento que temos da escola no sentido amplo de instituição educativa permite-nos identificar nela os seguintes traços: grupo de pessoas, finalidade explicita, divisão de trabalho, pretensão de racionalidade e ação eficaz, regulação de competências de cada membro, hierarquia de funções, planejamentos das ações educativas, estratégias para qualidade do ensino, ordenação das relações interpessoais, democratização do acesso, etc., ou seja, existe uma divisão funcional de tarefas entre a equipe gestora que é definida como cargos ou posto.

Alguns desses traços são de competência das ações do coordenador pedagógico, e é sobre este profissional ou esta pessoa que exerce esta função/cargo que queremos ressaltar neste texto, uma vez que se percebe e compreende uma preocupação/inquietação com a qualidade de ensino dos tempos atuais.

O planejamento curricular é uma tarefa contínua que acontece na escola para se alcançar a autonomia e qualidade de ensino dentro da instituição. Desse planejamento surge, em níveis específicos, o planejamento de ensino com atividades didáticas sistematizadas e metódicas concebidas pelo professor junto a seus alunos para a obtenção de objetivos definidos. A partir desse pressuposto entende-se que o coordenador pedagógico perpassa o educacional, caracterizando-se como um trabalho de assessoria ao professor, no que diz respeito ao planejamento, acompanhamento, controle, avaliação e atualização do desenvolvimento do processo de ensino e aprendizagem beneficiando as equipes docentes e discentes.

Segundo Carneiro (2002), pode-se dizer que a função precípua do coordenador pedagógico é irradiar energia estimuladora para a manutenção de um clima participativo, auxiliando e promovendo a coordenação das atividades do processo pedagógico e sua atualização, pelo estudo e pelas práticas coletivas da comunidade inseridas no ambiente escolar. 


\section{DESENVOLVIMENTO}

Neste trabalho pretendemos analisar questão referente ao estudo do curso "formação pela escola" no contexto do desenvolvimento das atuais politicas publica educacional. Para identificar com precisão o objetivo deste estudo a inquietação teve como base os documentos que foram disponibilizados para estudos e analise sobre o papel participativo do cidadão nos programas e ações do FNDE de maneira clara, objetiva e eficiente, possibilitando assim que as mudanças aconteçam.

A partir dessas análises me veio a seguinte inquietação com relação à Coordenação Pedagógica das escolas públicas: como se realizar o trabalho do coordenador pedagógico nas escolas municipais da cidade de Porto Seguro de modo a obter êxito apesar dos impasses e da instabilidade de cargo e/ou função?

No Brasil, na década de 1920, surgiu a função de Coordenador Pedagógico. Tal função surgiu com a proposta de equilibrar, hierarquizar propostas e competências pedagógicas. A pessoa do coordenador pedagógico apresenta um processo técnico que visa alcançar a qualidade de ensino por meio do domínio dos fundamentos da política educacional e do currículo. Tem uma função de suma importância para uma melhor qualidade educacional, promovendo conhecimento e estímulos à atuação profissional dos professores, subsidiando-os com apoio técnico e material, acompanhando de perto o desenvolvimento dos alunos, verificando a avaliação que acontece no ambiente de ensino em que está inserido.

No cenário atual o antigo supervisor, hoje denominado coordenador pedagógico, caracteriza-se como aquele profissional articulador do processo educativo, um educador que, engajado no (PPP) Projeto Político Pedagógico da Escola, colabora para a garantia de uma educação de qualidade para os alunos das camadas populares. A despeito de toda significância de suas funções e atuações, percebe-se que seu cargo é de uma instabilidade tão grande na visão do sistema educacional que acaba colaborando para o declínio da aprendizagem nas instituições de ensino. 
Analisaremos a regulamentação do exercício da profissão do Coordenador Pedagógico na Lei de Diretrizes e Base da Educação Nacional e em outras leis pertinentes ao caso de estudo aqui.

De acordo com o Art. 22 da Lei n 11.494/2007, são considerados profissionais do magistério:

Aqueles que exercem atividades de docência e os que oferecem suporte pedagógico direto ao exercício da docência, incluídas as de direção ou administração escolar, planejamento, inspeção, supervisão, orientação educacional e coordenação pedagógica. Para que possam ser remunerados com recursos do Fundeb esses profissionais deverão atuar na educação básica pública, no respectivo âmbito de atuação prioritária dos Estados e Municípios, conforme estabelecido nos $\S \S 2^{\circ}$ e $3^{\circ}$ do Art. 211, da Constituição. (BRASIL, 2007).

É importante destacar que a cobertura destas despesas poderá ocorrer, tanto em relação aos profissionais integrantes do Regime Jurídico Único do Estado ou Município, quanto aos regidos pela Consolidação das Leis do Trabalho - CLT, além daqueles que se encontram, formal e legalmente, contratados em caráter temporário, na forma da legislação vigente.

No grupo dos profissionais do magistério estão incluídos todos os profissionais da educação básica pública, sem distinção entre professor de jovens e adultos, da educação especial, da educação indígena ou quilombola e professor do ensino regular. Todos os profissionais do magistério que estejam em efetivo exercício na educação básica pública podem ser remunerados com recursos da parcela dos $60 \%$ do Fundeb, observando-se os respectivos âmbitos de atuação prioritária dos Estados e Municípios, conforme estabelecido nos $\S \S 2^{\circ}$ e $3^{\circ}$ do Art. 211 da Constituição.

Além do exposto, a Resolução ํo 01/2008 do Conselho Nacional de Educação considera que, dos profissionais que dão suporte pedagógico direto à atividade de docência, são considerados profissionais do magistério, para fins de recebimento da 
parcela dos $60 \%$, somente os licenciados em Pedagogia, ou os formados em nível de pós-graduação e os docentes designados nos termos de legislação e normas do respectivo sistema de educação.

O Sistema Educacional da cidade de Porto Seguro é composto por 107 escolas públicas, sendo que, 118 (cento e dezoito) coordenadores possuem uma coordenação atuante na rede de ensino, isso por que as escolas de grande porte apresenta necessidade de ter mais de um coordenador. No município somente vinte e dois (22) coordenadores exerce função efetiva, os demais coordenadores que estão em atuação nas escolas foram encaminhados obedecendo alguns critérios de organização do departamento pedagógica da Secretaria de Educação, geralmente por indicação do gestor escolar, indicação do setor pedagógico, desvio de função comprovado por laudo médico, etc.

O que se questiona é que quando surge situação de problema pedagógico dentro do ambiente escolar, principalmente com relação a remanejamento ou ausência/falta do professor regente em sala de aula, a primeira função que se pensa em desarticular é a do coordenador pedagógico, não se faz uma avaliação quanto ao desenvolvimento do trabalho já realizado no corpo docente e discente da escola, usando da insignificância para com esse profissional, uma vez que o município não articula concurso público para essa função escolar há vários anos e, por conta disso a grande maioria dos coordenadores em exercício não ocupa um cargo efetivo, são indicados, remanejados e, às vezes, nomeados.

Outra questão é com relação ao relacionamento do diretor e coordenador no ambiente da escola, pois ainda que tenham funções distintas, ambos são responsáveis por garantir o bom desenvolvimento das atividades escolares promovendo condições necessárias para uma aprendizagem de qualidade, para isso, é fundamental que a dupla gestora trabalhe em conjunto no planejamento e no acompanhamento do cotidiano escolar.

Quando surge algum impasse entre essa dupla de gestão infelizmente somente o gestor é compreendido na maioria das vezes, e a depender das suas petições, que 
muitas vezes são de cunho pessoal e não profissional, são rigorosamente atendidas, deixando sempre as ações pedagógicas em segundo plano, e sempre quem fica no prejuízo é o aluno.

Muitas vezes esse profissional é remanejado de suas funções por conta de uma organização de rede promovido geralmente pelas secretarias de educação, e logo após envia ás escolas pessoas para dar continuidade há um trabalho que não foi concluído por conta de algumas negligencias de gestão, dificultando assim o bom resultado pedagógico do ano letivo.

A educação é entendida como prática transformadora e democrática que busca a excelência visa a procedimentos didáticos e metodológicos centrados nos interesses, necessidades, e características dos membros de seu processo, tendo o aluno como agente principal desse processo, o que inviabiliza certas ações/atitudes de alguns gestores/administradores no processo educacional.

Faz-se importante salientar que de acordo com os PCN's (1998), as escolas têm como função potencializar o desenvolvimento de todas as capacidades, de modo a tornar o ensino mais humano, mais ético, mais capaz. Assim, o sistema deve criar condições que sejam capazes de incorporar o desenvolvimento de ações, que levem a quem for de direito reconhecer a realidade e criar mudanças nesta visão para alcançar os objetivos esperados.

\section{CONSIDERAÇÕES FINAIS}

A Lei Maior estabelece normas gerais sabre a realizações de concursos públicos no âmbito da administração direta e indireta. Com base na Lei Ordinária oㅜ 13.809 de 04 de dezembro de 2017, Art. 2º entende-se que o município de Porto Seguro precisa dar ênfase a essa lei, obedecendo a seus critérios.

As Secretarias Municipais de Educação precisam ver os Coordenadores Pedagógicos como um importante ponto de apoio na gestão da instituição de ensino, dando-Ihes autonomia em suas funções de maneira a cumprir com $o$ que os 
estudiosos/pesquisadores dessa temática explicitam quanto a um profissional que trabalha fazendo o uso de tal autonomia.

Dentro da ótica defendida pelo autores/pesquisadores podemos salientar que à medida que a função do Coordenador Pedagógico se torna cada vez mais instável, ou seja, suscetível de tombar, cair, virar, que não é constante, que muda com frequência etc., faz com que traga para os dias atuais uma imagem de definição negativa quanto à qualidade de educação dentro das instituições de Ensino Público.

Isso nos leva a refletir que o Coordenador Pedagógico desenvolve um papel importante para transformar os espaços educacionais em um colaborador de excelência na formação do cidadão, além de tudo pode promover mudanças significativas na Qualidade da Educação Pública.

\section{REFERÊNCIAS BIBLIOGRÁFICAS}

BRASIL. Constituição da República Federativa do Brasil de 1988. Senado Federal: Brasília, 1998.

. Fundo Nacional de Desenvolvimento da Educação (FNDE). Caderno de Estudos do Curso Competências Básicas. Fundo Nacional de Desenvolvimento da Educação. 4ª Ed., Atual, Brasília: FNDE, 2013.

. Lei de Diretrizes e Bases da EDUCAÇÃO Nacional - LDBEN 9.394/96, de 20 de dezembro de 1996. Senado Federal: Brasília, 1996.

. Lei no 11.494/2007. Senado Federal: Brasília, 2007.

. Lei Ordinária no 13.809 de 04 de dezembro de 2017. Senado Federal: Brasília, 2017.

. Parâmetros Curriculares Nacionais - PCN's. Senado Federal: Brasília, 1998. 
- Resolução no 01/2008 do Conselho Nacional de Educação. Senado Federal: Brasília, 2008.

CARNEIRO, Moacir Alves. LDB fácil: leitura crítica compreensiva artigo a artigo.7.ed Petrópolis. RJ: Vozes.2002.

KANT IMMANUEL (1724-1804). E a critica da razão pura. 4aㅡ ed. Prefácio à tradução portuguesa, introdução e notas: Alexandre Fradique MOURUJÃO. Tradução: Manuela Pinto dos SANTOS e Alexandre Fradique MOURUJÃO. Lisboa: Fundação Calouste Gulbenkian, 1997, p. 30.

MOREIRA e RIZZOTTI (2009, p.15), PROGESTÃO: Como gerenciar os recursos financeiros? Ana Maria Albuquerque Moreira, José Roberto Rizzotti; coordenação geral Aglaê de Medeiros Machado. - Brasília.

PLOCCO, V.M.N.S. O Coordenador Pedagógico e o Cotidiano da Escola. 4⿳亠丷厂 Ed. São Paulo: Edições Loyola, 2006.

SAMPAIO. Aline de Oliveira. Caderno de Estudos da Especialização, PósGraduação. Coordenação Pedagógica. A.V.M. Instituto, Brasília - DF, 2011.

Enviado: Agosto, 2018.

Aprovado: Agosto, 2019. 